\title{
El protagonismo de Tetzcoco en la Conquista a través del lente de Fernando de Alva Ixtlilxóchitl
}

\author{
The Main Role of Tetzcoco in the Conquest Through \\ the Perspective of Fernando de Alva Ixtlilxóchitl
}

\author{
Clementina BATTCOCK \\ https://orcid.org/0000-0002-9899-1214 \\ Instituto Nacional de Antropología e Historia (México) \\ Dirección de Estudios Históricos \\ cbattcock@yahoo.com.ar
}

\section{Sergio Ángel VÁSQUEZ GALICIA}

https://orcid.org/0000-0002-1901-220X

Universidad Nacional Autónoma de México (México)

Facultad de Filosofía y Letras

sergiovasquez@filos.unam.mx

\section{Resumen}

Integrante de un núcleo de autores nahuas de finales del siglo XVI y principios del XVII, descendientes de los antiguos grupos gobernantes de la cuenca de México, Fernando de Alva Ixtlilxóchitl hizo en sus obras una importante valoración de la historia prehispánica considerando narrativas que partían de Tetzcoco y los tetzcocanos como centrales en los procesos políticos de la región, además de presentarlos como aliados fundamentales de las tropas capitaneadas por Hernán Cortés. Este estudio presenta discusiones en torno a la intencionalidad de su escritura y el contexto político de la época como ejes centrales de su marco interpretativo, y busca contribuir con una serie de reflexiones críticas a los argumentos dados sobre la visión explicativa del autor sobre su pasado y su linaje. Además, destaca el papel medular de Ixtlilxóchitl como fuente en las consideraciones historiográficas que líneas de discusión recientes, como la "historiografía novohispana de tradición indígena" y la "conquista indígena de Mesoamérica”, han hecho sobre nuestras percepciones respecto del colapso de Tenochtitlan y del desarrollo del periodo novohispano.

Palabras clave: crónica, Fernando de Alva Ixtlilxóchitl, Tetzcoco, Conquista indígena de Mesoamérica, historiografía novohispana de tradición indígena.

\begin{abstract}
Fernando de Alva Ixtlilxóchitl was a member of a nucleus of Nahua authors from the late sixteenth and early seventeenth centuries who were descendants of the ancient ruling groups in the Basin of Mexico. Ixtlilxóchitl made in his works a meaningful appraisal of pre-Hispanic history considering narratives that started out from Tetzcoco and the Tetzcocans as main actors in the political processes of that region. Moreover, he depicted them as essential allies of the army commanded by Hernán Cortés. This article discusses about the intentionality of his writing and how the political and historical production context is a central axis of his interpretive framework. It also
\end{abstract}


contributes critical reflections to the arguments given about the author's explanatory vision of his past and his lineage. In addition, the article highlights the role of Ixtlilxóchitl as a key source in historiographical considerations of ongoing discussions, such as the ones made by the "New Spanish historiography of indigenous tradition" and the "Indigenous Conquest of Mesoamerica" about the collapse of Tenochtitlan and the early development of the Colonial period.

Keywords: chronic, Fernando de Alva Ixtlilxóchitl, Tetzcoco, Indigenous Conquest of Mesoamerica, New Spanish historiography of indigenous tradition.

\section{Introducción}

Según las fechas convencionales, el 22 de abril de 2019 se cumplieron cinco siglos del desembarco hispano en las costas del actual Veracruz, y para el 13 de agosto de 2021 habrán transcurrido las mismas centurias de la derrota mexica en Tlatelolco. Tales efemérides han puesto en boga el tema de la conquista de México y han hecho aflorar polémicas, tal como ocurrió en 1992, con el llamado "V centenario" del encuentro o descubrimiento de América.

En este contexto de debate académico hay una revisión crítica de las ponderaciones y análisis del suceso llamado Conquista; se han propuesto otras fuentes y otras formas teóricas de examinarlas, a fin de cuestionar las "verdades" convencionales y desentrañar, desde otras perspectivas, el desarrollo del proceso y los múltiples sentidos que la conciencia histórica de distintas épocas y lugares le ha dado.

Por lo menos desde 2007, la vertiente denominada "Conquista indígena de Mesoamérica" se ha propuesto explicar, desde otro ángulo, la identidad de los conquistadores del hipotético "México antiguo". Con fuentes archivísticas y crónicas con sustratos de tradición mesoamericana, autores como Michel Oudijk, Laura Matthew, Matthew Restall, Robinson A. Herrera y Florine L. Asselbergs, entre otros, ${ }^{1}$ han evidenciado el protagonismo de los pueblos indígenas en la lucha contra Tenochtitlan.

En el plano analítico de la "Conquista indígena de Mesoamérica”, el caso tetzcocano ofrece amplias posibilidades, ya que los registros que se conservan en varios cuerpos documentales contrastan con las narrativas que centran su atención en la perspectiva nahua tenochca. Tal es el caso de la

${ }^{1}$ Son abundantes los estudios que actualmente siguen el enfoque propuesto en el libro Indian Conquistadors, por ello sólo mencionamos a los autores participantes en esta obra colectiva. Véase Laura Matthew y Michel Robert Oudijk, eds., Indian Conquistadors: Indigenous Allies in the Conquest of Mesoamerica (Norman: University of Oklahoma Press, 2007). 
historia que, en 1608, culminó el cronista Fernando de Alva Ixtlilxóchitl: el Compendio histórico de los reyes de Tetzcoco. ${ }^{2}$ Inserto en su "Decimotercera relación", y con gran prolijidad y recursos narrativos, da cuenta de la participación aculhua en la llamada conquista de México. A partir de la información del Compendio histórico... recientemente Pablo García Loaeza escribió un trabajo dedicado específicamente al papel de Tetzcoco en el proceso de conquista. El autor hace evidentes las disputas internas en el gobierno aculhua durante los últimos años del Posclásico Tardío y relata la llegada de los europeos, su recibimiento por los señores tetzcocanos, la expulsión de la alianza hispano-indígena de la cuenca de México y las circunstancias en las que Tetzcoco se alió con los castellanos. Asimismo, García ordena la información del Compendio histórico... sobre el número de soldados, gente de apoyo y recursos que ofrecieron los aculhuas para conseguir el sometimiento de Tenochtitlan y Tlatelolco. Finalmente, sintetiza la información sobre la participación de Tetzcoco en las conquistas de Huatusco, Tuxtepec, Coatzacoalcos, Tututepec, Colima, Pánuco y Guatemala, además de narrar la expedición a Las Hibueras y el trascendente papel de la cabecera del Aculhuacan en la conquista espiritual. ${ }^{3}$

El trabajo de García Loaeza representa un meritorio esfuerzo de rescate del importante y multifacético papel de Tetzcoco en la Conquista; sin embargo, en su afán por dar voz a los aculhuas, su reconstrucción histórica termina por seguir puntualmente la versión del Compendio histórico... y omite la indispensable crítica a su contenido. Así, da por buenas las elevadas cifras de soldados y gente de apoyo tetzcocana que supuestamente participaron en la conquista de los mexicas, y comulga con la idea de que Cortés formó una dupla indisoluble con Fernando Cortés Ixtlilxóchitl. ${ }^{4}$

${ }^{2}$ En 1608 Alva Ixtlilxóchitl puso a consideración de las autoridades del cabildo indígena de Otumba y Cuauhtlatzinco la veracidad de su Compendio histórico. Edmundo O'Gorman, "Estudio introductorio", en Fernando de Alva Ixtlilxóchitl, Obras históricas. Incluye el texto completo de las llamadas Relaciones e Historia de la nación chichimeca en una nueva versión establecida con el cotejo de los manuscritos más antiguos que se conocen (México: Universidad Nacional Autónoma de México, Instituto de Investigaciones Históricas, 1975), v. I, 210. (En adelante será referida como ed. de O’Gorman.)

${ }^{3}$ Pablo García Loaeza, “Tetzcoco en la conquista”, en De Catemahco a Tetzcoco: origen y desarrollo de una ciudad indígena, ed. de Javier Eduardo Ramírez López (Texcoco: Diócesis de Texcoco, 2017), 93-117.

${ }^{4}$ Sobre las elevadas cifras, es claro que en la elaboración de la zanja para echar los bergantines no pudieron participar 400000 aculhuas, como afirma Alva Ixtlilxóchitl y retoma García Loaeza, pues en el Posclásico Tardío la cuenca de México no contaba con más de 1200000 habitantes. Jeffrey R. Parsons, “Arqueología regional en la cuenca de México: una 
Ciertamente, el Compendio histórico... es fundamental para ponderar la participación de los aculhuas en las conquistas de Mesoamérica, pero no por ello ha de tenerse como la única obra que da "cuenta cabal de [esa] etapa de la historia de Tetzcoco". ${ }^{5}$ Para avanzar con pasos más firmes en el estudio de la participación aculhua, hay que reparar primero en que amén de ser fuentes potenciales de información, las obras históricas de Alva Ixtlilxóchitl son en principio reelaboraciones del recuerdo del pasado, hechas a partir de los materiales disponibles en la época y, no en menor medida, producto de los propios intereses de un autor que vivía en el seno de las inestables instituciones novohispanas que en sus vastas jurisdicciones reconocían y suprimían privilegios y beneficios a individuos y corporaciones, en un complejo entramado de relaciones sociales. Por ello es fundamental acercarnos al contenido de las obras con mirada inquisitiva y analítica respecto de los elementos discursivos de la escritura de un autor que, como otros muchos, estaba ávido de alcanzar el reconocimiento a su linaje, a su historicidad y a su pertenencia social.

Sobre la propuesta, enfoque y metodología de este trabajo

Al mediar el siglo xx, Edmundo O’Gorman y Ramón Iglesia ${ }^{6}$ insistieron en que las obras de historia eran más que simples "minas de donde extraer ciertos datos y noticias". ${ }^{7}$ A través del análisis historiográfico, buscaron estudiar la forma en que el contexto, la experiencia de vida y el pensamiento de los autores novohispanos se proyectan en sus obras. ${ }^{8}$

En 2003, José Rubén Romero Galván, bajo la influencia del pensamiento de O’Gorman e Iglesia, acuñó la categoría Historiografía novohispana de

estrategia para la investigación futura", Anales de Antropología, v. 26, n. 1 (México, 1989): 205. Sobre las decisiones conjuntas entre Hernán Cortés y Fernando Cortés Ixtlilxóchitl, García señala que sigue la versión de Alva Ixtlilxóchitl; sin embargo, no la cuestiona a sabiendas de que el cronista buscó representar a su antepasado como el verdadero artífice de la conquista, García Loaeza, “Tetzcoco”, 101-102.

5 García Loaeza, “Tetzcoco”, 100 y 102.

${ }^{6}$ Edmundo O'Gorman, La historia natural y moral de las Indias del P. José de Acosta (Estudio que se publicará como prólogo a la nueva edición de dicha obra) (México: Fondo de Cultura Económica, 1940), I-LXXXv; Ramón Iglesia, "La historia y sus limitaciones” y "Estado actual de las ciencias históricas”, en Ramón Iglesia, El hombre Colón y otros ensayos (México: Fondo de Cultura Económica, 1994), 26-31 y 32-54.

7 O'Gorman, La historia natural y moral, $\mathrm{x}$.

${ }^{8}$ Iglesia, “Estado actual...”, en Iglesia, El hombre Colón, 30. 
tradición indígena, ${ }^{9}$ aplicable a las obras resultantes del contacto entre la forma de hacer y concebir la historia de los europeos y los grupos mesoamericanos, y cuyo rasgo distintivo es conservar elementos de ambas tradiciones. ${ }^{10}$ En esta categoría se ubican manuscritos de los últimos años del siglo XVI hasta mediados del XVII, escritos por los descendientes de los antiguos pipiltin, incluidos los del propio Ixtlilxóchitl.

Los autores de tradición indígena recibieron, por un lado, la educación dentro de la tradición cultural mesoamericana, aún subsistente en relatos orales y otras fuentes históricas materiales, y en la cultura europea, ${ }^{11}$ inculcada en instituciones donde estudiaron, y preservada en textos a los que pudieron acceder a través de bibliotecas conventuales, los cuales mantenían una fuerte impronta de la tradición hispano-cristiana de las narrativas épicas de conquista. Escribieron en caracteres latinos, a veces en español, a veces en náhuatl u otra lengua autóctona, historias que relataban el devenir de los centros de poder que habían gobernado sus ancestros, ${ }^{12}$ por lo que están centradas en un grupo social específico: los propios pipiltin que generación tras generación perdían espacios dentro del gobierno novohispano. ${ }^{13}$ Rasgos indiscutiblemente occidentales fueron la autoría, el ordenamiento del contenido histórico en capítulos y seguir como eje narrativo la historia cristiana de salvación. ${ }^{14}$ La lectura minuciosa de estas historias pone de manifiesto que las intenciones que alentaron a sus autores deben ser contextualizadas en las dinámicas propias de su posición social. ${ }^{15}$

Desde la perspectiva del análisis historiográfico de obras de tradición indígena, proponemos que la representación del proceso de Conquista en

9 José Rubén Romero Galván, “Introducción”, en Historiografía mexicana. Volumen I. Historiografía novohispana de tradición indígena, coord. de José Rubén Romero Galván (México: Universidad Nacional Autónoma de México, Instituto de Investigaciones Históricas, 2003), 9-20.

${ }^{10}$ Romero Galván, “Introducción”, 12.

${ }^{11}$ Romero Galván, "Introducción”, 16.

12 Romero Galván, "Introducción”, 16.

${ }^{13}$ Miguel Pastrana Flores, "Historiografía de tradición indígena”, en Historia general ilustrada del Estado de México, dir. de María Teresa Jarquín Ortega y Manuel Miño Grijalva (Toluca: Gobierno del Estado de México, Secretaría de Educación del Gobierno del Estado de México, Poder Judicial del Estado de México, LVIII Legislatura del Estado de México, Consejo Editorial de la Administración Pública Estatal, 2011), v. 2, 61.

${ }^{14}$ Yukitaka Inoue Okubo, “Crónicas indígenas: una reconsideración sobre la historiografía novohispana temprana”, en Indios, mestizos y españoles. Interculturalidad e historiografía en la Nueva España, coord. de Danna Levin y Federico Navarrete (México: Universidad Autónoma Metropolitana Azcapotzalco, 2007), 55-96.

${ }^{15}$ Romero Galván, “Introducción”, 16-17. 
las crónicas de Alva Ixtlilxóchitl está inscrita en las formas de escribir la historia vigentes en su tiempo y condicionadas por su formación intelectual y cultural y su pertenencia social. Para comprender su interpretación, debemos considerar su conocimiento de las antiguas tradiciones indígenas que le fueron transmitidas por su linaje, así como su incorporación a la cultura europea, y desde ambas vías, poner atención a las propias preocupaciones del autor. Recordemos que Alva Ixtlilxóchitl escribió casi cien años después de la caída de Tenochtitlan, y que en ese momento la antigua cabecera del Aculhuacan ya había perdido su prestigio político y económico, pues la nobleza indígena novohispana luchaba por conservar los privilegios que recibió de la Corona al inicio del gobierno colonial. En el caso particular del cronista aculhua, buscaba conservar el cacicazgo de San Juan Teotihuacan, y con ello validar el estatus de su familia en la administración indígena.

En su interpretación, Alva Ixtlilxóchitl planteó a los tetzcocanos como pieza clave de la conquista armada y espiritual de Mesoamérica. A este proceso interpretativo lo consideramos un acto de sublimación del pasado, pues en él los ideales e intereses del historiador fueron el motor para exaltar la participación aculhua en la Conquista. ${ }^{16}$

Desde el punto de vista metodológico, planteamos que además de la "Decimotercera relación" del Compendio histórico..., es necesario tomar en cuenta otras de sus crónicas para comprender su planteamiento, pues en ellas desarrolló toda una composición narrativa con múltiples figuras retóricas —dramatización, omisión, denostación, exaltación, etcétera- ${ }^{17}$ tanto para investirse de autoridad en la escritura sobre la Conquista, como para engrandecer la participación de los tetzcocanos. Por ello, pondremos especial atención en cómo se refiere a los eventos de ese pasado que le pareció relevante rememorar, y destacaremos los significativos silencios de su interpretación.

16 Álvaro Matute y Evelia Trejo, "Lo sublime, un recurso para creer en la historia”, Revista de la Universidad de México, n. 18 (2005): 5-16.

${ }_{17}$ No se conocen documentos que nos indiquen las características de la preparación que Alva Ixtlilxóchitl recibió en la construcción de discursos, el uso de estrategias narrativas y de figuras retóricas; sin embargo, tenemos ejemplo de la que recibieron otros indígenas de élite. Véase Citlalli Bayardi, "Figuras retóricas en el Coloquio de los doce de fray Bernardino de Sahagún y el colectivo indígena del Colegio de Santa Cruz de Tlatelolco, 1564”, en El Colegio de Tlatelolco, síntesis de historias, lenguas y culturas, ed. de Esther Hernández y Pilar Máynez (México: Editorial Grupo Destiempos, 2016), 123-148. 
Sobre los nuevos abordajes de las obras de Alva Ixtlilxóchitl

Durante las últimas décadas, los historiadores han mostrado un creciente interés en Fernando de Alva Ixtlilxóchitl; esto se ha reflejado en los análisis historiográficos, la traducción de sus obras, la discusión sobre sus orígenes, etcétera. En La construcción del pasado indígena de Tetzcoco. De Nezahualcóyotl a Alva Ixtlilxóchitl, ${ }^{18}$ y a través de un análisis concienzudo y serio, el investigador francés, Patrick Lesbre ha incidido en que la condición de mestizo del autor ha hecho que se le tache de "demasiado hispano" y que su obra no haya sido realmente justipreciada.

Hace un par de años, Amber Brian, Bradley Benton, Peter V. Villella y Pablo García Loaeza publicaron una traducción al inglés de la Historia de la nación chichimeca, ${ }^{19}$ a partir de los manuscritos originales del cronista aculhua. En la introducción subrayan algunos aspectos significativos de su vida y entorno y revaloran su obra.

Algunos de los especialistas mencionados han retomado la obra de Ixtlilxóchitl desde una perspectiva relacionada con la crítica literaria, sus propuestas van desde estudios de las estructuras narrativas de los textos del cronista, ${ }^{20}$ hasta el análisis de su estilo discursivo, cuyo origen está en la retórica con la que los señores tetzcocanos solicitaron mercedes a la Corona española. ${ }^{21}$ Caso aparte son los artículos adentrados en la "evolución"

${ }^{18}$ Patrick Lesbre, La construcción del pasado indígena de Tetzcoco. De Nezahualcóyotl a Alva Ixtlilxóchitl (México: Secretaría de Cultura, Instituto Nacional de Antropología e Historia; Zamora: El Colegio de Michoacán; México: Centro de Estudios Mexicanos y Centroamericanos, 2016), 537 p. Originalmente fue la tesis doctoral del autor. Patrick Lesbre, "Historiographie acolhua du premier siècle de la colonisation. Genèse d'une culture métisse" (tesis de doctorado en Estudios Latinoamericanos, Université de Toulouse-Le Mirail, Institut Pluridisciplinaire d'Études sur l'Amérique Latine à Toulouse, 1997).

${ }^{19}$ Fernando de Alva Ixtlilxóchitl, History of Chichimeca Nation. Don Fernando de Alva Ixtlilxochitl's Seventeenth-Century Chronicle of Ancient Mexico, ed. y trad. de Amber Brian, Bradley Benton, Peter Villella et al. (Norman: University of Oklahoma Press, 2019), $334 \mathrm{p}$.

${ }^{20}$ Véase Pablo García Loaeza, "Deeds to be Praised for All Time: Alva Ixtlilxochitl's Historia de la nación chichimeca and Geoffrey of Monmouth's History of the Kings of Britain", Colonial Latin American Review, v. 23, n. 1 (2014): 53-69, http://dx.doi.org/10.1080/10609 164.2013.877251, consultado: 21 de noviembre de 2020 .

${ }^{21}$ Véase Peter Villella, "The Last Acolhua: Alva Ixtlilxochitl and Elite Native Historiography in Early New Spain”, Colonial Latin American Review, v. 23, n. 1 (2014): 18-36, http://dx.doi.org/10.1080/10609164.2013.877249, consultado: 21 de noviembre de 2020 . 
académica de Alva y que incluso cuestionan su etnicidad:22 además de aquellos que se centran en la relación de sus escritos con las dinámicas de archivo y otros que ponen atención en la gran importancia del legado historiográfico del autor tetzcocano. ${ }^{23}$ En The Legacy of Rulership in Fernando de Alva Ixtlilxochitl's Historia de la nación chichimeca, ${ }^{24}$ Leisa A. Kauffmann realiza una importante contribución, pues al tiempo que concede que Alva, desde luego, exalta la historia de Tetzcoco, no lo hace como un producto de su propia invención, sino que abreva de una larga tradición historiográfica que se fue adaptando a los cambios en el contexto histórico novohispano.

Ahora bien, estas tendencias han impactado en la producción académica mexicana, la cual atraviesa un renovado interés por la conquista, debido, en parte, a la conmemoración del llamado "V centenario". En 2018, Héctor Alejandro Costilla Martínez publicó un libro bajo el sello de la Benemérita Universidad Autónoma de Puebla, en el que abordó los textos de Alva en tanto obras literarias cuya escritura, híbrida, combina un discurso épico occidental con otro mestizo. ${ }^{25}$ Más recientemente, el Centro de Estudios Literarios Antonio Cornejo sacó a la luz: Nuevos asedios a la Conquista de México. ${ }^{26}$ El libro colectivo da cuenta de algunas posturas de la "nueva historia de la conquista", que revalora las fuentes y redefine al suceso como un enfrentamiento entre facciones con intereses definidos y no como un pleito bilateral entre indios y españoles. Específicamente, los artículos de los ya mencionados Benton y García Loaeza abordan el tema de lo tetzcocano: el primero habla de la durabilidad de los sistemas políticos hispanos, que en el periodo virreinal limitaron los beneficios obtenidos para el linaje de Ixtlilxóchitl, debido a las restrictivas dinámicas nahuas del poder.

${ }^{22}$ Véase Bradley Benton, “The Outsider: Alva Ixtlilxochitl's Tenuous Ties to the City of Tetzcoco", Colonial Latin American Review, v. 23, n. 1 (2014): 37-52, http://dx.doi.org/10.1 080/10609164.2013.877250, el 21 de noviembre de 2020.

${ }^{23}$ Entre éstos podemos citar las siguientes obras: Fernando de Alva Ixtlilxochitl and His Legacy, ed. de Galen Brokaw y Jongsoo Lee (Arizona: University of Arizona Press, 2016); y Amber Brian, Alva Ixtlilxochitl's Native Archive and Circulation of Knowledge in Colonial Mexico (Nashville, Tennessee: Vanderbilt University Press, 2016).

${ }^{24}$ Leisa A. Kauffmann, The Legacy of Rulership in Fernando de Alva Ixtlilxochitl's Historia de la nación chichimeca (Albuquerque: University of New Mexico Press, 2019), 296 p.

${ }^{25}$ Héctor Alejandro Costilla Martínez, Fernando de Alva Ixtlilxóchitl y la reconstrucción de la grandeza texcocana. Escritura híbrida y discurso épico en Historia de la nación chichimeca (México: Benemérita Universidad Autónoma de Puebla, 2018), 135 p.

${ }^{26}$ Pablo García Loaeza y Héctor Costilla Martínez, eds., Nuevos asedios a la conquista de México (Lima: Centro de Estudios Literarios Antonio Cornejo, 2021). 
Por su parte, García se remite a la "Decimotercera relación" para analizar el carácter híbrido de la obra del cronista, quien se vale de elementos caballerescos europeos para resaltar las virtudes y las hazañas de su antepasado, Fernando Cortés Ixtlilxóchitl.

Algunas notas sobre la vida de Fernando de Alva Ixtlilxóchitl

El cronista aculhua pertenecía a uno de los principales linajes pipiltin que se remontaba hasta Nezahualcóyotl y Nezahualpilli por vía materna. ${ }^{27}$ Fue el segundo hijo de Ana Cortés Ixtlilxóchitl, quien heredó el cacicazgo de San Juan Teotihuacán, ${ }^{28}$ y del español Juan Navas Pérez de Peraleda. Su tatarabuelo fue Fernando Cortés Ixtlilxóchitl, hijo de Nezahualpilli, y personaje fundamental en las obras del historiador aculhua. ${ }^{29}$

En 1597 su madre heredó y tuvo que defender las tierras del cacicazgo de San Juan Teotihuacan que ya habían sido invadidas por españoles, pillis y macehuales, cuyo acceso a ellas era determinante para proteger su subsistencia, y con ello sostener una presencia política en ese territorio, lo cual es una estampa del frágil momento que vivía la antigua nobleza indígena para procurar sus privilegios. ${ }^{30}$ En 1610 su esposo solicitó amparo al virrey Luis de Velasco (1539-1617) y al año siguiente, el historiador aculhua entró en la querella como representante de sus padres. ${ }^{31}$ En julio de 1611, presentó la "Probanza de doña Ana Cortés", ${ }^{32}$ en la que trece testigos avalaron

${ }^{27}$ Bradley Brenton, The Lords of Tetzcoco. The Transformation of Indigenous Rule in Postconquest Central Mexico (Nueva York: Cambridge University Press, 2017), 21-25.

${ }^{28}$ Véase Guido Münch, El cacicazgo de San Juan Teotihuacan durante la Colonia 1521-1821 (México: Secretaría de Educación Pública, Instituto Nacional de Antropología e Historia, 1976); Sergio Ángel Vásquez Galicia, "La identidad de Fernando de Alva Ixtlilxóchitl a través de su memoria histórica. Análisis historiográfico" (tesis de doctorado en Historia, Universidad Nacional Autónoma de México, Facultad de Filosofía y Letras, 2013), 110-119; Jongsoo Lee, "Colonial Writings and Indigenous Politics in New Spain: Alva Ixtlilxochitl's Chronicles and the Cacicazgo of Teotihuacan”, en Fernando de Alva Ixtlilxochitl and His Legacy, 122-152.

${ }^{29}$ Sergio Ángel Vásquez Galicia, "Aportes a la biografía del historiador tetzcocano Fernando de Alva Ixtlilxóchitl”, Revista Fuentes Humanísticas, año 27, n. 53 (julio-diciembre 2016): 148, http://zaloamati.azc.uam.mx/handle/11191/5227, consultado: 17 de febrero de 2020. Véase árbol genealógico.

30 "Diligencias de información y probanza de doña Ana Cortés Ixtlilxóchitl”, Alva Ixtlilxóchitl, Obras históricas, ed. de O’Gorman, v. II, 294.

${ }^{31}$ La documentación puede ser consultada en "Diligencias de información", v. II, apéndices 5,8 y 16.

32 “Diligencias de información”, v. II, 295-301. 
la legítima posesión del cacicazgo, así como el justicia mayor de San Juan concedió la protección solicitada. ${ }^{33}$

La noble estirpe de Alva Ixtlilxóchitl también le dio acceso a ciertos cargos. El 7 de diciembre de 1612 fue nombrado juez gobernador de Tetzcoco, espacio político desde el cual podía intervenir en los conflictos entre los habitantes de dicho territorio emitiendo disposiciones administrativas que lo ubicaron en una posición lo suficientemente polémica frente a los habitantes tetzcocanos, quienes no vieron con gusto su elección para dicho puesto. Un año después pidieron que lo reemplazara don Pedro de Arellano, con el alegato de que Ixtlilxóchitl era falto de brío y "no le estiman los indios ni se da maña a las cosas del servicio personal ni a la cobranza de los tributos". ${ }^{34}$ Benton ha mostrado que los lazos familiares de Alva Ixtlilxóchitl con la nobleza tetzcocana fueron tenues, y por eso, a un mes de su toma de posesión fue destituido. ${ }^{35}$ No obstante, tenía relaciones sólidas con las autoridades españolas y así logró nuevas comisiones. De 1617 a 1618 desempeñó el cargo de juez gobernador de Tlalmanalco, y entre 1620 y 1622 de Chalco. ${ }^{36}$ Asimismo, fue intérprete en el Tribunal de Indios de la capital novohispana ${ }^{37}$ y solicitador de causas en el Ayuntamiento. ${ }^{38}$

Se ignoran los detalles sobre la educación de Ixtlilxóchitl; sin embargo, José Rubén Romero Galván ha propuesto la posibilidad de que el cronista fuera instruido en alguna institución para hijos de españoles. ${ }^{39}$ Anteriormente, Ángel María Garibay Kintana argumentó que el historiador aculhua se formó en el Imperial Colegio de la Santa Cruz de Tlatelolco, junto a otros

33 "Diligencias de información”, v. II, 332 y 333.

34 "Año de 1613. Expediente formado para que Pedro de Arellano retenga el título de gobernador de Texcoco, y proceda a las obligaciones que le corresponden”, Archivo General de la Nación (en adelante AGN), Indiferente Virreinal, caja 3066, exp. 8, f. 1v.

35 “Año de 1613", f. 1r. También Benton, “The Outsider”, 46.

36 "Nombramiento de Fernando de Alva Ixtlilxóchitl como juez gobernador de Tetzcoco" y "Mandamiento del virrey marqués de Gelves a don Fernando de Alva Ixtlilxóchitl. Que haga públicas las averiguaciones respecto a don Antonio de la Mota”, en Manuscritos de Texcoco, comp. de Antonio Peñafiel (México: Innovación, 1979), 14 y 16-17, y "Nombramiento de Juez Gobernador de Tlalmanalco a favor de don Fernando de Alva Ixtlilxóchitl y prórroga por un año", Alva Ixtlilxóchitl, Obras históricas, ed. de O’Gorman, v. II, 336-337.

${ }^{37}$ O'Gorman, "Estudio introductorio", v. I, 27.

38 "Memoria testamentaria de Antonia Gutiérrez, esposa de don Fernando de Alva Ixtlilxóchitl”, Alva Ixtlilxóchitl, Obras históricas, ed. de O’Gorman, v. II, 390.

${ }^{39}$ José Rubén Romero Galván, "Fernando de Alva Ixtlilxóchitl”, en Historiografía mexicana. Volumen I, 351-366. 
cronistas indígenas. ${ }^{40}$ Más recientemente, Sergio Ángel Vásquez Galicia planteó que el cronista asistió con los jesuitas en San Gregorio, o al Colegio Máximo de San Pedro y San Pablo de la ciudad de México. ${ }^{41}$ En cualquier caso, no existen documentos que acrediten las propuestas sobre la institución en la que se educó; sin embargo, lo importante es resaltar que tuvo acceso al conocimiento necesario para escribir cinco obras historiográficas de gran complejidad y las herramientas literarias indispensables para redactar los romances al Rey don Sancho y El cerco de Zamora. ${ }^{42}$ Como los programas educativos de la época se apegaban a la más pura tradición universitaria medieval, Ixtlilxóchitl al menos debió cursar el trivium, que estaba integrado por gramática, dialéctica y retórica; ${ }^{43}$ este conocimiento lo capacitó en la estrategia discursiva con la que explicó la Conquista. ${ }^{44}$

Asimismo, en las obras del cronista hay referencias bíblicas y modelos escriturísticos que explican al mundo indígena como parte del devenir cristiano universal. ${ }^{45}$ Esto no significa que el historiador tetzcocano tuviera acceso directo a la Biblia, pues en su época y contexto su lectura estaba reservada a los ministros eclesiásticos, conocedores del latín. Seguramente, Alva obtuvo sus conocimientos de pasajes bíblicos gracias a su formación cristiana, la plática con religiosos y su educación institucional. ${ }^{46}$

${ }^{40}$ Amber Brian, "The Alva Ixtlilxochitl Brothers and the Nahua Intellectual Community", en Texcoco: Prehispanic and Colonial Perspectives, coord. de Jongsoo Lee y Galen Brokaw (Boulder: University Press of Colorado, 2014), 201-202.

${ }^{41}$ Sergio Ángel Vásquez Galicia, “Conceptos, ideas y modelos europeos y de tradición indígena en la construcción de un buen gobernante. Nezahualcóyotl en las crónicas de Fernando de Alva Ixtlilxóchitl”, en El gobernante en Mesoamérica, coord. de María Elena Vega Villalobos y Miguel Pastrana Flores (México: Universidad Nacional Autónoma de México, Instituto de Investigaciones Históricas, 2018), 162.

42 "Poesías de don Fernando de Alva Ixtlilxóchitl”, en Alva Ixtlilxóchitl, Obras históricas, ed. de O’Gorman, v. II, 267-274. Sobre el manejo literario de Alva, véase García Loaeza, "Ixtlilxóchitl, flor de la caballería en la conquista de México", en Nuevos asedios, 208-212.

${ }^{43}$ Sobre el aprendizaje del trivium entre los franciscanos, véase José Rubén Romero Galván, "El Colegio de Tlatelolco, universo de encuentros culturales", en El Colegio de Tlatelolco..., 17; sobre su aprendizaje entre los jesuitas, véase Elsa Cecilia Frost, "Los colegios jesuitas", en Historia de la vida cotidiana en México. II. La ciudad barroca, coord. de Antonio Rubial (México: Fondo de Cultura Económica; México: El Colegio de México, 2005), 312.

${ }^{44}$ Vásquez Galicia, “Conceptos”, 164-189.

${ }^{45}$ Jongsoo Lee y Galen Brokaw, "Fernando de Alva Ixtlilxochitl and Colonial Indigenous Historiography from the Conquest to the Present", en Fernando de Alva Ixtlilxochitl and His Legacy, 8.

${ }^{46}$ Vásquez Galicia, "La identidad”, 176. Juan José Daneri considera que "un letrado como Alva” tuvo acceso a varias ediciones de la Vulgata que circulaban en la Nueva España, pero estando ésta en lengua latina nada garantiza que el cronista tuviese los conocimientos 
En las obras de Alva Ixtlilxóchitl, la tradición europea se fusionó con la forma de registrar la historia entre los grupos indígenas, la cual conoció en el seno familiar. El autor recurrió intensamente a la tradición oral tetzcocana y a varios códices, entre los que se pueden contar el Códice Xólotl, el Mapa Quinatzin y el Mapa Tlotzin, ${ }^{47}$ y a los memoriales, anales, cantos e historias de autores indígenas para construir sus obras. ${ }^{48}$ En este sentido, las cinco crónicas de Ixtlilxóchitl son un buen ejemplo de la historiografía novohispana de tradición indígena, pues en ellas dos modos de hacer y concebir la historia se encontraron para dar origen a una nueva, en la que exaltó los logros de su propia familia como una forma de justificar, defender y exigir los privilegios a los que tenía derecho. Según Benton, Ixtlilxóchitl intentó registrar, de manera casi hagiográfica, las acciones de su linaje dentro del pasado prehispánico y en su papel en el mundo virreinal. ${ }^{49}$

\section{El Compendio histórico de los reyes de Tetzcoco de Fernando de Alva Ixtlilxóchitl: ubicación y características}

El trabajo historiográfico de Alva Ixtlilxóchitl ha sido objeto de múltiples interpretaciones, desde Carlos de Sigüenza y Góngora hasta la actualidad. ${ }^{50}$ A partir del descubrimiento de sus manuscritos originales, en 1982 por Wayne Ruwet, ${ }^{51}$ se han cotejado las ediciones de sus obras con los nuevos manuscritos y se ha planteado la necesidad de reeditar sus trabajos y retomar el análisis cuidadoso de distintos temas abordados. Para el caso de la Con-

necesarios para leerla. Véase Juan José Daneri, “¿Tloque Nahuaque o Dios desconocido? El problema de la traducción en la Historia de la nación chichimeca de Fernando de Alva Ixtlilxóchitl", en Morada de la palabra: homenaje a Luce y Mercedes López-Baralt, v. 1, ed. de William Mejías López (San José: Universidad de Puerto Rico, 2002), 518.

${ }^{47}$ Para un estudio pormenorizado de estos códices véase: Eduardo de Jesús Douglas, In the Palace of Nezahualcoyotl. Painting Manuscripts, Writing the Pre-Hispanic Past in Early Colonial Period Tetzcoco, Mexico (Austin: University of Texas Press, 2010), 17-40.

${ }^{48}$ Sobre las fuentes de Alva Ixtlilxóchitl, véase Vásquez Galicia, “La identidad”, 161-181.

${ }^{49}$ Benton, "The Outsider", 48.

${ }^{50}$ Para un análisis detallado de este discurrir histórico, véase Vásquez Galicia, "La identidad", 23-61.

${ }^{51}$ Wayne Ruwet, "Los manuscritos de la Bible Society: su historia, redescubrimiento y contenido", en Manuscritos mexicanos, perdidos y recuperados, comp. de Clementina Battcock, Rodrigo Martínez Baracs y Salvador Rueda Smithers (México: Secretaría de Cultura, Instituto Nacional de Antropología e Historia, 2019), 13-25, y Amber Brian, “The Original Alva Ixtlilxóchitl Manuscripts at Cambridge University”, Colonial Latin American Review, v. 23, n. 1 (2014): 84101, http://dx.doi.org/10.1080/10609164.2013.877253, consultado: 24 de abril de 2015. 
quista, la obra fundamental es el Compendio histórico..., debido al detalle y la prolijidad con que aborda el tema. A ella vale la pena dedicarle algunas líneas.

El Compendio histórico... ${ }^{52}$ es uno de los documentos que componen los tres volúmenes que el gobierno mexicano decidió llamar Códice Chimalpahin, una vez que los adquirió de la British and Foreign Bible Society, entre 2014 y $2015 .^{53}$ Se sabe que el documento fue entregado a manos británicas por José María Luis Mora (1794-1850) a cambio de biblias impresas. ${ }^{54}$ Mora sustrajo los manuscritos de manera ilegal del Colegio de San Ildefonso, aunque previamente los tres tomos pertenecieron a la Biblioteca del Colegio Máximo de San Pedro y San Pablo, donde Lorenzo Boturini los copió entre 1737 y 1739. Fue don Carlos de Sigüenza y Góngora (1645-1700) el que reunió una voluminosa documentación sobre el pasado antiguo de la Nueva España ${ }^{55}$ y tras su muerte legó al Colegio Máximo "entre quatrocientos y setenta libros". ${ }^{56}$ Existe la firme posibilidad de que Sigüenza las adquiriera de manos de Juan de Alva Cortés, hijo del historiador tetzcocano, cuando el sabio novohispano se desempeñó como su apoderado legal (1680). ${ }^{57}$

52 El presente análisis de sus obras está basado en nuestra transcripción modernizada de los manuscritos autógrafos contenidos en el llamado Códice Chimalpahin. En cuanto a la consulta de la obra del cronista aculhua, resulta indispensable la lectura de la digitalización del original, debido a las múltiples variaciones encontradas en la edición realizada por Edmundo O’Gorman. Cabe mencionar que hace pocos años se publicó una edición al inglés de la "Decimotercera relación" del Compendio histórico basada en los manuscritos autógrafos de Ixtlilxóchitl contenidos en el Códice Chimalpahin. Los editores fueron Amber Brian, Bradley Benton y Pablo García Loaeza y fue publicada bajo el título The Native Conquistador. Alva Ixtlilxochitl's Account of the Conquest of New Spain. Lamentablemente la edición no es útil para el análisis de los especialistas por varios motivos. En primer lugar, porque los editores no exponen sus criterios editoriales y de traducción; en segundo, porque Ixtlilxóchitl pensó su obra en español; y en tercero, porque al publicar de manera aislada la "Decimotercera relación" se mutila el discurso histórico que el cronista tetzcocano construyó en torno a la Conquista. Fernando de Alva Ixtlilxóchitl, [Thirteenth Relation: On the Arrival of the Spaniards and the Beginning of the Law of the Gospel]. The Native Conquistador: Alva Ixtlilxochitl's Account of the Conquest of New Spain, ed. y trad. de Amber Brian, Bradley Benton y Pablo García Loaeza (Pensilvania: Pennsylvania State University Press, 2015).

${ }^{53}$ Sobre la riqueza documental de estos volúmenes, véase Manuscritos mexicanos.

${ }^{54}$ Véase Susan Schroeder, "Father José María Luis Mora, Liberalism, and the British and Foreign Bible Society in Nineteenth-Century Mexico", The Americas, v. 50, n. 3 (enero 1994): 377-397.

${ }^{55}$ Ruwet, "Los manuscritos", 14.

${ }^{56}$ Gabriel López de Sigüenza, “Carta proemio”, en Carlos de Sigüenza y Góngora, Oriental planeta evangélico epopeya sacro-panegyrica al apóstol grande de las Indias S. Francisco Xavier (México: Doña María de Benavides, 1700), 4.

57 O’Gorman, “Estudio introductorio”, v. I, 40-41; también Brian, Alva Ixtlilxochitl's Native Archive, 70. 
La presencia de don Carlos como compilador de los manuscritos del llamado Códice Chimalpahin, y la de Alva Ixtlilxóchitl como autor de algunos de los textos, se corrobora con sus rúbricas en diferentes obras. Para ser precisos, el Compendio histórico... ocupa 68 fojas del volumen II, entre el folio 147 y el 215, y la primera página ostenta la firma de Sigüenza y Góngora (véase la figura 1).

En el volumen I se ubica la Relación sucinta en forma de memorial de las historias de Nueva España y sus señoríos hasta el ingreso de los españoles, en la que figura la rúbrica del cronista tetzcocano $(9 \mathrm{v})$ (véase la figura 2). ${ }^{58}$

El Compendio histórico... está estructurado en trece relaciones de dispar desarrollo, inicia con un primer escrito, sin título, que explica la migración de los grupos chichimecas y su legitimación como grupos hegemónicos en la cuenca de México; luego continúa con la "Relación de los gigantes", "Relación de los tultecas", "Relación de los reyes monarcas chichimecas", "Relación del rey Xolotl, 3er. poblador”, "Relación del rey Nopaltzin, 2do. chichimecatl tecuhtli", "Relación de Tlotzin, 3er. chichimecatl tecuhtli", "Relación del rey Texchotlalatzin, 5to. chichimecatl tecuhtli", "Relación del rey Yxtlilxuchitl, 6 chichimecatl tecuhtli", "Relación del gran Neçahualcoyotl, 7 chichimecatl tecuhtli", "Relación del rey Neçahualpiltzintli, 8 chichimecatl tecuhtli" y "Relación de la venida de los españoles y principio de la ley evangélica”. Cada relación narra las luchas por el territorio y la construcción del poderío de los líderes que consolidaron su autoridad bajo el "título" de chichimecatecuhtli.

La estructura de la obra no es fortuita: no todas las relaciones tienen el mismo desarrollo, algunas son más pequeñas y, sin lugar a duda, la más extensa es la "Decimotercera". El orden de estas relaciones tiene un sentido lineal, las doce primeras son las que permiten contextualizar y legitimar los sucesos que se abordan en la última. Es claro que esta es la más importante, pues los hechos que narra le permiten a Alva justificar su argumento. No obstante, las cinco crónicas de Ixtlilxóchitl son necesarias para comprender su planteamiento de la Conquista, pues en ellas desarrolló la estrategia discursiva con la que sublimó la intervención de Tetzcoco para responder a sus intereses políticos, económicos y sociales contemporáneos. No es fortuito que Alva pusiera a dictamen y obtuviera del cabildo indígena de Otumba y Cuauhtlatzinco la acreditación de su Compendio histórico... como

58 Para una descripción de los manuscritos, véase Pablo García Loaeza, "Los manuscritos de don Fernando de Alva Ixtlilxóchitl”, en Manuscritos mexicanos, 180-181. 


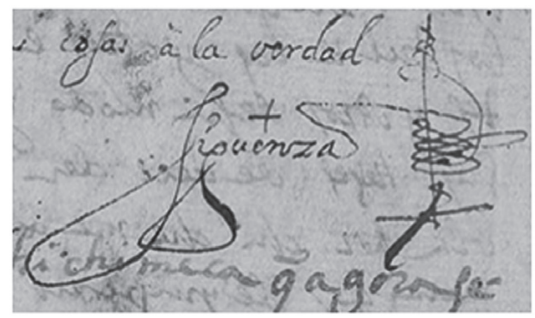

Figura 1. Firma de Carlos de Sigüenza y Góngora. Compendio histórico de los reyes de Tetzcoco, en Códice Chimalpahin, v. II, f. $1 \mathrm{r}$

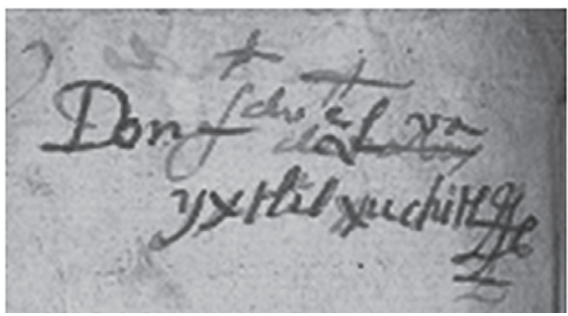

Figura 2. Firma de Fernando de Alva Ixtlilxóchitl. Relación sucinta en forma de memorial, en Códice Chimalpahin, v. I, f. $85 \mathrm{v}$

una "historia verdadera" en $1608,{ }^{59}$ apenas unos años antes de entrar a la defensa del cacicazgo de su madre y de obtener los diversos cargos que desempeñó para la administración indígena novohispana.

Tetzcoco en la conquista según Fernando de Alva Ixtlilxóchitl

En las siguientes páginas explicaremos algunos de los argumentos y herramientas discursivas que Alva Ixtlilxóchitl empleó para asumir a los tetzcocanos como los autores de la conquista material y espiritual de Mesoamérica, y que hicieron del Compendio histórico... una herramienta para defender sus privilegios y estatus, con tal de acceder a cargos importantes en la administración novohispana.

\section{El argumento de autoridad}

No es casualidad que fuera en la Sumaria relación de todas las cosas en donde el autor señalara sus cualidades como historiador y la autoridad de sus

59 “Testimonio que dan el gobernador, alcaldes, regidores del pueblo de San Salvador Quatlacinco del año de mil seiscientos ocho, el día diez y ocho de noviembre, a don Fernando de Alva Cortés [sic], aprobando su historia que escribió del origen, grandeza y hazañas de los tultecas, chichimecas y naciones sujetas a ellos, hasta la conquista de México y pacificación de las tres provincias, declarando que dicha historia concuerda con las que tienen los pueblos de Otumba, con muchas otras particulares”, en Alva Ixtlilxóchitl, Obras históricas, ed. de O'Gorman, v. I, 517-521. 
trabajos sobre la Conquista. ${ }^{60}$ Esa fue la primera obra que redactó, entre 1600 y 1610, y, por lo tanto, la idónea para sentar las bases de su plan argumentativo.

El primer paso para convencer a sus lectores fue evidenciar las deficiencias de las obras españolas, como las Cartas de relación de Hernán Cortés (1485-1547) y las Décadas de Antonio de Herrera y Tordesillas (ca. 15491625). ${ }^{61}$ Para Ixtlilxóchitl, los escritos de los ibéricos eran imperfectos por tres carencias de los autores: su desconocimiento del náhuatl, pues "no entendiendo bien la lengua y lo que los viejos les dicen" ${ }^{2}$ consignan información imprecisa, y "por decir una cosa dicen otra" y unos "dicen cesta y otros ballesta". ${ }^{63}$ La segunda fue su ignorancia del funcionamiento del sistema de escritura indígena. Mientras que la tercera fue la falta de crítica a sus fuentes, pues, según explica el propio autor, tomaron como verdadero el testimonio de los informantes indígenas, sin percatarse de que entre ellos existía un pacto para falsear la información a los españoles, o en palabras del cronista, para no "decir el hecho de la verdad". ${ }^{64}$

Por otra parte, el aculhua destacó que las obras de los cronistas oficiales de Indias eran tendenciosas, tal y como ejemplifica con la de Antonio de Herrera, pues la base de su información fueron los testimonios de Cortés y sus soldados. Alva incluso los acusó de callar eventos importantes de la Conquista, como los abusos que cometieron contra los naturales, pues "si los cronistas españoles no los han escrito será porque los que les dieron las

${ }^{60}$ Sobre el problema de la conceptualización del autor y sus narrativas, véanse Rolena Adorno, Guaman Poma. Literatura de resistencia en el Perú colonial (México: Fondo de Cultura Económica, 1991); José Antonio Mazzotti, Coros mestizos del Inca Garcilaso. Resonancias andinas (Lima: Fondo de Cultura Económica, 1996); Walter Mignolo, Historias locales / diseños globales. Colonialidad, conocimientos subalternos y pensamiento fronterizo (Madrid: Akal, 2002).

${ }^{61}$ En el capítulo xc de la Sumaria re[lación], mejor conocida como Historia de la nación chichimeca, el cronista de Tetzcoco dejó constancia de conocer "las cartas y relaciones que [Hernán Cortés] envió a su majestad [Carlos V]”. En el mismo capítulo, Ixtlilxóchitl se refirió a las obras de Herrera y Tordesillas como "su crónica”. Fernando de Alva Ixtlilxóchitl, Sumaria re[lación], f. 127v, en Códice Chimalpahin, v. II, Biblioteca Nacional de Antropología e Historia (en adelante BNAH).

${ }^{62}$ Fernando de Alva Ixtlilxóchitl, "Declaración del autor sobre sus informantes”, en Sumaria relación de todas las cosas, f. 16v, en Códice Chimalpahin, v. I, BNAH.

${ }^{63}$ Alva Ixtlilxóchitl, "Declaración del autor sobre sus informantes”, Sumaria relación de todas las cosas, f. 16v, en Códice Chimalpahin, v. I, BNAH.

${ }^{64}$ Este convenio lo refiere en Alva Ixtlilxóchitl, "Declaración del autor sobre sus informantes”, Sumaria relación de todas las cosas, f. 17r, en Códice Chimalpahin, v. I, BNAH. 
relaciones eran los hechores y por su honra lo habían de callar", ${ }^{65}$ y no registrar los hechos heroicos de los guerreros de estas tierras. ${ }^{66}$ Además, las ambiciones de Cortés provocaban que en las crónicas de los ibéricos se hiciera una sesgada representación del proceso, ya que en ellas él aparecía como la pieza central y protagónica de la hazaña más importante de sus tiempos: la conquista de Tenochtitlan. Por eso, el cronista tetzcocano señaló que Cortés siempre procuró "matar a los señores y aún a sus hijos, y oscurecer sus hechos y darse a sí solo gloria...”; ${ }^{67}$ según Alva, así lo hizo con su antepasado, a quien no mató, pero sí olvidó mencionar en sus Cartas de relación. ${ }^{68}$

Una vez que desacreditó las crónicas hispanas, Ixtlilxóchitl explicó cuáles eran sus cualidades de historiador. Como si se tratara de pares opuestos, argumentó contar con herramientas de las que carecían los españoles. En la "Declaración del autor sobre sus informantes", incluida en la Sumaria relación de todas las cosas, el cronista aculhua confesó que, cuando comenzó a redactar sus obras, él tampoco sabía náhuatl: “...y otros, no entendiendo bien la lengua y lo que los viejos les dicen, como a mí me ha sucedido muchas veces con los naturales, siendo nacido y criado entre ellos..... ${ }^{69}$ Sin embargo, al final del texto señala que con esfuerzo y dedicación llegó a conocerla tan bien como los propios naturales: “...y cierto que con tener las historias en mi poder, y saber la lengua como los mismos naturales, porque me crié con ella, y conocer a todos los viejos principales desta tierra, para haber de sacar esto en limpio me ha costado harto estudio y trabajo...." ${ }^{70}$ Asimismo, en la "Dedicatoria" perteneciente a la Sumaria re[lación] indicó que desconocía el sistema de escritura indígena, pero con tesón obtuvo los conocimientos suficientes para interpretar los códices por sí mismo:

...he conseguido mi deseo con mucho trabajo, peregrinación y suma diligencia en juntar las pinturas de las historias y anales, y los cantos con que las observaban; y sobre todo, para poderlas entender, juntando y convocando a muchos principales de esta Nueva España, los que tenían fama de conocer y saber las historias referidas; y de todos ellos sólo dos hallé entera relación y conocimiento de las pinturas y

${ }^{65}$ Alva Ixtlilxóchitl, Compendio, f. 68r, en Códice Chimalpahin, v. II, BNAH.

${ }^{66}$ Alva Ixtlilxóchitl, Compendio, f. 60r, en Códice Chimalpahin, v. II, BNAH.

${ }^{67}$ Alva Ixtlilxóchitl, Compendio, f. 60r, en Códice Chimalpahin, v. II, BNAH.

${ }^{68}$ Alva Ixtlilxóchitl, Compendio, f. 60r, en Códice Chimalpahin, v. II, BNAH.

${ }^{69}$ Alva Ixtlilxóchitl, "Declaración del autor sobre sus informantes”, Sumaria relación de todas las cosas, f. 16r, en Códice Chimalpahin, v. I, BNAH. Las cursivas son nuestras.

70 Alva Ixtlilxóchitl, "Declaración del autor sobre sus informantes”, Sumaria relación de todas las cosas, f. 16r, en Códice Chimalpahin, v. I, BNAH. 
caracteres, y que daban verdadero sentido a los cantos, que por ir compuestos con sentido alegórico y adornados de metáforas y similitudes, son dificilísimos de entender; con cuya ayuda pude después con facilidad conocer todas las pinturas e historias y traducir los cantos en su verdadero sentido... ${ }^{11}$

Ixtlilxóchitl consideró que su esfuerzo de investigación respaldaba la calidad de sus trabajos, pues había tenido acceso a fuentes angulares de los procesos narrados, tanto orales (Lucas Cortés Calanta, Jacobo de Mendoza Tlaltecatzin, Gabriel de Segovia Acapipiotzin, Francisco Ximénez, Alonso Izhuezcatocatzin Axayacatzin y Agustín de la Fuente) ${ }^{72}$ como escritas y pictográficas. El origen y la naturaleza de las fuentes se ajustaban a las intenciones del cronista aculhua: eran testimonios de indígenas principales y ancianos, considerados los guardianes de la memoria; habían sido escritas, pintadas o narradas por los protagonistas de los sucesos o por sus descendientes y, finalmente, coincidían con una "historia original" cuyo guion él seguía. Según Edmundo O’Gorman, Ixtlilxóchitl se refería a tres fuentes documentales centrales: el Códice Xólotl y los mapas Quinatzin y Tlotzin; los tres son de tradición aculhua, así que, para nuestro historiador, las fuentes tetzcocanas eran las indicadas para conocer la Conquista. ${ }^{73}$

\section{Las omisiones significativas}

Después de demostrar que sus obras sí tenían autoridad, Ixtlilxóchitl se dispuso a establecer las bases para argumentar que los tetzcocanos fueron los verdaderos aliados de los españoles. ${ }^{74}$ Para ello, el primer recurso fue la omisión. En sus obras, el cronista aculhua representó el encuentro entre

${ }^{71}$ Alva Ixtlilxóchitl, Sumaria re[lación], "Dedicatoria”, f. 1r, en Códice Chimalpahin, V. II, BNAH.

72 Para las características de sus informantes, véase Alva Ixtlilxóchitl, “Declaración del autor sobre sus informantes”, Sumaria relación de todas las cosas, f. 15r-17r, en Códice Chimalpahin, v. I, BNAH. Sobre la posibilidad de que Agustín de la Fuente fuera su informante, véase Gordon Whittaker, "The Identities of Fernando de Alva Ixtlilxóchitl”, en Fernando de Alva Ixtlilxochitl and His Legacy, 65.

${ }^{73}$ Estas síntesis de características también se basan en la "Declaración del autor sobre sus informantes".

${ }^{74}$ Desde la perspectiva de la conquista indígena de Mesoamérica se ha cuestionado la idea de ver a los grupos mesoamericanos como aliados, pues ellos se reconocían como conquistadores, no obstante, en este análisis la retomamos porque fue la manera en que el propio Alva Ixtlilxóchitl la planteó. 
españoles e indígenas como carente de conflictos. Por ejemplo, el Compendio histórico... señala que, luego de reponerse en Tlaxcala de la expulsión de Tenochtitlan, Cortés volvió a la cuenca y:

...ya que llegaba cerca de Tezcoco, le salieron a recibir algunos caballeros, y entre ellos el infante Ixtlilxóchitl [...] el cual se holgó de verlos [...] Y llegados dentro de la ciudad, los aposentaron en los palacios del rey Nezahualcoyotzin, en donde cupo muy a gusto todo el ejército, y se les dio todo lo necesario éste y los demás días que en la ciudad estuvieron. ${ }^{75}$

Además de las Cartas de relación, Ixtlilxóchitl conoció La conquista de México de Francisco López de Gómara (1511-1559). ${ }^{76}$ En ambas obras se relatan los enfrentamientos entre españoles y tetzcocanos. ${ }^{77}$ Asimismo, tuvo acceso a una copia del Lienzo de Tlaxcala, ${ }^{78}$ en donde quedó registrada la defensa de la capital aculhua y los sacrificios de españoles en su Templo Mayor (véase la figura 3).

En el centro de la imagen un indígena principal, ataviado con máxtlatl y tilma, lleva un estandarte en la mano. La glosa dice: "Tetzcoco yauani (yauh ni) xyxtlilxochitzin", que quiere decir "Ixtlilxochitzin fue -o los llevó- a Tetzcoco”. En la parte baja se ve a Hernán Cortés a caballo, acompañado de dos guerreros indígenas tlaxcaltecas. Adelante se observa al extremeño sometiendo a los tetzcocanos. En la parte superior derecha se encuentra nuevamente a Cortés, quien observa la cabeza de un caballo sacrificado.

Coincidimos con Patrick Lesbre en que la lámina destaca la ayuda de Ixtlilxóchitl a los castellanos, ${ }^{79}$ pero lo que nos interesa poner de relieve es que el historiador aculhua omitió intencionalmente los enfrentamientos entre españoles y tetzcocanos, y en particular la violenta conquista de Tetzcoco que

75 Alva Ixtlilxóchitl, Compendio, f. 27r, en Códice Chimalpahin, v. II, BNAH.

${ }^{76}$ Alva Ixtlilxóchitl, "Declaración del autor sobre sus informantes”, Sumaria relación de todas las cosas, f. 16r, en Códice Chimalpahin, v. I, BNAH.

77 Cortés destaca la muerte de muchos cristianos a manos de los tetzcocanos, Hernán Cortés, “Tercera carta de relación”, en Cartas y documentos (México: Porrúa, 1963), 122. Gómara narra la violenta conquista de Tetzcoco. Francisco López de Gómara, La historia de las Indias y conquista de México, v. II (Zaragoza: Agustín Millán, 1552), f. 70v-73r.

${ }^{78} \mathrm{La}$ referencia a esta obra es la siguiente: "En la pintura que el día de hoy guarda el cabildo de esta señoría [de Tlaxcala], se halla que en esta sazón se bautizaron los señores de ella por Juan Díaz, clérigo, y fue su padrino el capitán Cortés...”. Alva Ixtlilxóchitl, Sumaria re[lación], f. 116r, en Códice Chimalpahin, v. II, BNAH.

${ }^{79}$ Lesbre, “Historiographie...”, 424. 


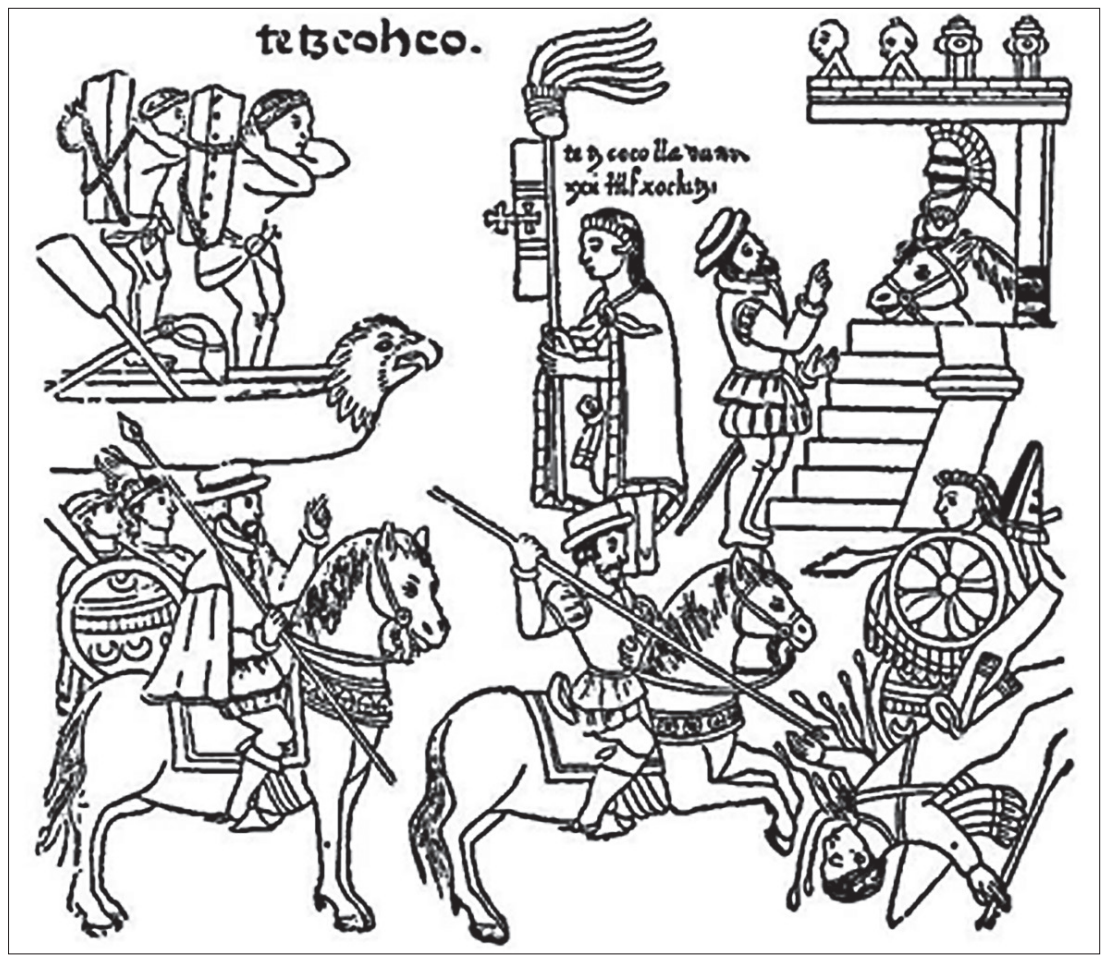

Figura 3. Conquista de Tetzcoco. Lámina 41, Lienzo de Tlaxcala, edición de Alfredo Chavero (México: Lit. del Timbre 1892).

conoció en sus fuentes, con tal de centrarse en el recibimiento pacífico y en el apoyo que los aculhuas, encabezados por su antepasado, dieron en la Conquista. Esto último es muy significativo, porque, de acuerdo con Jongsoo Lee, en esta parte del proceso Ixtlilxóchitl no era el protagonista, como lo pinta Alva, pues estaba bajo el mando de Tecocoltzin, hijo de Nezahualpilli al que Cortés reconociera como chichimecatecuhtli. En este sentido, la intención de Alva fue minimizar a Tecocoltzin para ponderar a su antepasado. ${ }^{80}$

Igualmente, es necesario reconocer que en la escritura de Ixtlilxóchitl se deja entrever una clara intencionalidad narrativa que prepara la estructura formal de una alianza entre el chichimecatecuhtli aculhua y los europeos, reconociendo la autoridad cristiana de estos últimos. Por ejemplo, en la "Docena relación" del Compendio histórico..., Alva Ixtlilxóchitl mencionó los ordenamientos bajo los cuales el hijo y sucesor chichimecatecuhtli de

${ }^{80}$ Lee, "Colonial Writings and Indigenous Politics”, 138. 
Nezahualcóyotl, de nombre Nezahualpilli y quien gobernó hasta poco antes del desembarco de Cortés, fue quien presagió el advenimiento de los españoles, pues: "Declaró a sus vasallos y a los demás reyes cómo esta tierra había de ser de los hijos del sol, hombres valerosos e invencibles, y que tenían un señor el mayor del mundo, y que su Dios era el Tloque Nahuaque que era el Creador de todas las cosas, y que a esa causa no convenía ser contra ellos". ${ }^{81}$ Como se puede notar, Nezahualpilli instaló, desde su posición como gobernante aculhua, lo que podemos interpretar como una "alianza predestinada" que es tratada abundantemente en la "Decimotercera relación".

\section{Desacreditar al competidor}

El siguiente recurso argumentativo de Ixtlilxóchitl fue desacreditar a quienes disputaban a Tetzcoco el papel de aliados de los conquistadores: los tlaxcaltecas. Sobre esto, debemos recordar que la enemistad entre Tlaxcala y Tetzcoco comenzó cuando la Excan Tlahtoloyan realizó la conquista del valle de Puebla-Tlaxcala y terminó por rodear a los tlaxcaltecas. Luego, durante el proceso de sometimiento de los mexicas, ambos se aliaron con los españoles, así que años más tarde, los dos pueblos se representaron en sus historias como los máximos aliados en la Conquista. Alva Ixtlilxóchitl agregó a su relato el recurso de desacreditar a su competidor para convencer a sus lectores.

El historiador aculhua destacó aquellos defectos que le permitían descalificar a los tlaxcaltecas; los calificó de interesados, ladrones, ambiciosos ${ }^{82}$ y mentirosos; ${ }^{83}$ y los acusó de saquear Tetzcoco: "Y de camino los tlaxcaltecas saquearon la ciudad de Tezcoco y otros lugares, robando a los vecinos de noche sin ser sentidos y a tiempo que no se pudieron defender y librar sus haciendas de ellos". ${ }^{84}$ Pero el ejemplo que mejor sintetiza la construcción de esta mala imagen fue responsabilizarlos por la matanza en la fiesta de Tóxcatl; sobre esto dice: “...a pocos días fue una fiesta que llaman Toxcatl

${ }^{81}$ Alva Ixtlilxóchitl, Compendio, f. 22v, en Códice Chimalpahin, v. II, BNAH.

${ }^{82}$ Ixtlilxóchitl señala que lo único que le importaba a los tlaxcaltecas era el botín de guerra. Alva Ixtlilxóchitl, Compendio, f. 29r, en Códice Chimalpahin, v. II, BNAH.

${ }^{83}$ Ixtlilxóchitl culpa a los tlaxcaltecas de haber inventado que Motecuhzoma quería matar a los españoles. Alva Ixtlilxóchitl, Sumaria re[lación], f. 118v, en Códice Chimalpahin, V. II, BNAH.

${ }^{84}$ Alva Ixtlilxóchitl, Compendio, f. 43r, en Códice Chimalpahin, v. II, BNAH. 
[...] y en aquel día empezaron los mexicanos a hacer su fiesta como solían [...] Y estando haciendo sus fiestas, los indios de Tlaxcala dijeron a los españoles que no consintiesen hacer aquello, porque los querían matar, lo cual era traición que les levantaban los tlaxcaltecas". ${ }^{85}$

Señalar a los tlaxcaltecas como insidiosos y adjudicarles uno de los actos más reprobables de la Conquista, tanto para la moral cristiana como para la memoria tenochca, fue el punto clave para minimizar su colaboración. Este recurso es todavía más significativo si tomamos en cuenta que el autor conocía obras que plasmaban una imagen favorable de Tlaxcala, como el Lienzo de Tlaxcala y la Historia de la conquista de Tadeo de Niza de Santa María. ${ }^{86}$

\section{La exaltación de la alianza tetzcocana}

Habiendo infamado al tlaxcalteca, Ixtlilxóchitl ya estaba en posibilidad de construir una narración glorificada de la que él consideró como una sincera, bienintencionada e importante participación de Tetzcoco en la lucha de conquista; el autor exaltó a niveles inconmensurables tanto el apoyo como a los protagonistas aculhuas. La descripción dramática de los sucesos fue el primer paso.

Según el historiador, en las conquistas de Mesoamérica los tetzcocanos pasaron grandes miserias y hambre, pues sólo comían "yerbas y algunas frutillas silvestres" ${ }^{87}$ con tal de mantener bien abastecidos a Cortés y a los suyos. Además, Alva Ixtlilxóchitl destacó que la "gente de guerra" y "socorro" tetzcocana estuvo dispuesta a morir por millares para ayudar a Cortés, tanto así que, según sus propias palabras, los muertos "[tiñeron] toda la laguna grande de sangre, que verdaderamente no parecía agua". ${ }^{88} \mathrm{Y}$ por si esto fuera poco, solicitó a sus pueblos sujetos estar pendientes por "si hubiese menester [de] socorro". ${ }^{9}$

Al mismo tiempo, el historiador aculhua aclaró que, ante la enorme desventaja numérica de los españoles, la ayuda de los guerreros tetzcocanos

${ }^{85}$ Alva Ixtlilxóchitl, Sumaria relación de todas las cosas, f. 79v, en Códice Chimalpahin, V. I, BNAH.

${ }^{86}$ Alva Ixtlilxóchitl, Sumaria re[lación], f. 115r, en Códice Chimalpahin, v. II, BNAH.

${ }^{87}$ Alva Ixtlilxóchitl, Compendio, f. 43r, en Códice Chimalpahin, v. II, BNAH.

${ }_{88}$ Alva Ixtlilxóchitl, Compendio, f. 33v, en Códice Chimalpahin, v. II, BNAH.

${ }^{89}$ Alva Ixtlilxóchitl, Compendio, f. 32v, en Códice Chimalpahin, v. II, BNAH. 
fue fundamental, pues "fuera imposible querer cuatro españoles sujetar un nuevo mundo tan grande y de tantos millares de gentes". ${ }^{90}$ Según explica, este apoyo permitió que "la ciudad de Mexico y otras partes [se ganaran] con menos trabajo y costa de lo que podía costar". ${ }^{91}$

\section{La exaltación del apóstol y el guerrero}

Para ajustar su interpretación a los intereses económicos, políticos y sociales que perseguía, Alva Ixtlilxóchitl ensalzó a su antepasado, Fernando Cortés Ixtlilxóchitl, como el más importante tetzcocano en la Conquista. En este sentido, tiene razón Benton al señalar que el historiador aculhua "tenía muchos motivos para exagerar y adornar el papel de Ixtlilxóchitl como aliado". ${ }^{92}$ Para comenzar con su argumentación, de la "Cuarta" a la "Docena relación" del Compendio histórico..., el aculhua explicó que fueron los legítimos chichimecatecuhtlis quienes engrandecieron a Tetzcoco. ${ }^{93}$ Por su parte, en la "Decimotercera relación" destacó a Cacama como un gobernante ilegítimo, impuesto por su tío Motecuhzoma Xocoyotzin, quien pretendía dominar todo el "imperio". ${ }^{44}$ Para Alva, era Cortés Ixtlilxóchitl el legítimo chichimecatecuhtli, por eso fue quien logró comprender la importancia de apoyar a los castellanos para establecer en estas tierras la ley evangélica. ${ }^{95}$

En consonancia con la retórica providencialista de la época, Ixtlilxóchitl representó a su tatarabuelo como uno de los instrumentos de Dios. En la Sumaria re[lación] planteó que la aparente coincidencia temporal entre el nacimiento de Carlos V en la ciudad de Gante y el de su tatarabuelo en Tetzcoco, en realidad era una muestra de la misteriosa forma en que el Creador trabaja, pues sólo preparaba la llegada de los que fueron: "instrumento principal para ampliar y dilatar la santa fe católica”. ${ }^{96}$ El historiador aculhua también forjó de su antepasado un apóstol o un doctrinero. Según el Compendio histórico..., Cortés Ixtlilxóchitl enseñaba: “...a sus hermanos

${ }^{90}$ Alva Ixtlilxóchitl, Compendio, f. 24v, en Códice Chimalpahin, v. II, BNAH.

${ }^{91}$ Alva Ixtlilxóchitl, Compendio, f. 32v, en Códice Chimalpahin, v. II, BNAH.

${ }^{92}$ Bradley Benton, "El provecho de la alianza: efectos a largo plazo de la participación tetzcocana en la conquista”, en Nuevos asedios, 66.

${ }^{3}$ Alva Ixtlilxóchitl, Compendio, f. 3v-23v, en Códice Chimalpahin, v. II, BNAH.

${ }^{94}$ Alva Ixtlilxóchitl, Compendio, f. 23v, en Códice Chimalpahin, v. II, BNAH.

${ }_{95}$ Alva Ixtlilxóchitl, Compendio, f. 52r, en Códice Chimalpahin, v. II, BNAH.

${ }^{96}$ Alva Ixtlilxóchitl, Sumaria re[lación], f. 87r, en Códice Chimalpahin, v. II, BNAH. 
y hermanas, deudos y parientes, la doctrina cristiana con más policía y las ceremonias, y términos al modo castellano [...] en donde les decía largas arengas y sermones, trayéndoles a la memoria grandes cosas, de tal manera que los enternecía con las palabras tan buenas, tan santas, que las decía como si fuera un apóstol, si se puede decir". ${ }^{97}$

Por otra parte, quizá basado en ideas caballerescas, ${ }^{98}$ el cronista dio cuenta de las dotes militares de su antepasado pues, según él, fue el más importante estratega y general; de ahí que hubiera sido "el gran amigo" de Cortés, ${ }^{99}$ amén de su consejero, pues el conquistador extremeño no tomaba decisiones tácticas sin consultarlo. Esto se representó en oraciones como: "Cortés, con acuerdo de Ixtlilxóchitl”, ${ }^{100}$ o "acordó Cortés y Ixtlilxóchitl”. ${ }^{101}$ Según el historiador tetzcocano, luchaban codo a codo "Cortés e Ixtlilxóchitl con sus soldados". ${ }^{102}$ No cabe duda de que el enaltecimiento de la ayuda que Cortés Ixtlilxóchitl prestó a la Conquista, alcanzó niveles excelsos en el campo de batalla, y es posible que tal representación tenga un fondo de verdad, como ha propuesto García, ${ }^{103}$ pues códices como el Mexicanus y la Tira de Tepechpan dan cuenta de que recibió algunos justos premios; ${ }^{104}$ sin embargo, no podemos tomar literalmente su información, ${ }^{105}$ pues es evidente que el historiador aculhua exageró la figura de su antepasado, a la que incluso le atribuyó la libertad de reprender a Cortés por tomar decisiones erróneas. ${ }^{106}$

El cronista del Aculhuacan conoció la Segunda y la Tercera carta de relación de Cortés; sin embargo, tomó distancia de ellas, pues consideró un agravio que el extremeño omitiera "las hazañas" de Fernando Cortés Ixtlilxóchitl: "Y me espanto de Cortés que, siendo este príncipe el mayor y más leal amigo que tuvo en esta tierra, que después de Dios con su ayuda y favor se ganó, [f. 36r] no diera noticia de él y de sus hazañas y heroicos hechos, siquiera a los escritores o historiadores para que no quedaran sepultados". ${ }^{107}$

${ }^{97}$ Alva Ixtlilxóchitl, Compendio, f. 51v, en Códice Chimalpahin, v. II, BNAH.

98 Sobre esto, véase García Loaeza, "Ixtlilxóchitl, flor”, 199.

${ }^{99}$ Alva Ixtlilxóchitl, Compendio, f. 34r, en Códice Chimalpahin, v. II, BNAH.

${ }^{100}$ Alva Ixtlilxóchitl, Compendio, f. 39v, en Códice Chimalpahin, v. II, BNAH.

${ }^{101}$ Alva Ixtlilxóchitl, Compendio, f. 44r, en Códice Chimalpahin, v. II, BNAH.

102 Alva Ixtlilxóchitl, Compendio, f. 37r, en Códice Chimalpahin, v. II, BNAH.

103 García Loaeza, “Ixtlilxóchitl, flor...”, 209.

${ }^{104}$ Benton, "El provecho de la alianza...”, 66.

105 García Loaeza, “Tetzcoco en la conquista”, 101-102.

${ }^{106}$ Alva Ixtlilxóchitl, Compendio, f. 38v, en Códice Chimalpahin, v. II, BNAH.

107 Alva Ixtlilxóchitl, Compendio, f. 35v-36r, en Códice Chimalpahin, v. II, BNAH. En el proceso de la conquista de Mexico Cortés sólo mencionó una vez a Fernando Cortés Ixtlilxóchitl. Véase Cortés, “Tercera carta de relación”, 160. 
Con esto, el conquistador no sólo pecaba de ingrato, sino que resultaba culpable de que la memoria de don Cortés Ixtlilxóchitl se perdiera sin remedio. Lo que era gravísimo, visto que por sus grandes gestas y "después de Dios, se ganó esta tierra". ${ }^{108}$

\section{Conclusiones}

Aunque Fernando de Alva Ixtlilxóchitl tuvo el sincero interés por preservar la memoria de los hechos heroicos de sus antepasados y de mostrar que los naturales formaban parte del plan que Dios tenía preparado para la humanidad, en el desarrollo de este trabajo pudimos observar que en sus obras historiográficas también armó toda una estrategia discursiva para encumbrar a sus ancestros como los protagonistas de la conquista material y espiritual de Mesoamérica. Su doble formación, tanto en la tradición indígena de la que fue heredero como en la europea en la que fue instruido a través de su adoctrinamiento, su educación institucionalizada y su lectura de obras europeas, le permitió hacerse de las herramientas discursivas necesarias para componer una narrativa que integró figuras retóricas con las que engrandeció hasta niveles inconmensurables la historia de sus antepasados. Con ellas descalificó las obras españolas sobre la Conquista y se envistió de la autoridad para narrar el tema; ignoró los episodios que comprometían la imagen de sus familiares como amigos de los españoles y desacreditó a otros actores indígenas de la Conquista, como los tlaxcaltecas o los linajes tetzcocanos ajenos al suyo, que entorpecían su propósito. Con todo esto, destacó a su tatarabuelo, Fernando Cortés Ixtlilxóchitl, como instrumento de Dios, como el más hábil guerrero y como el más virtuoso ejemplo de religiosidad.

Su sublimada historia de la participación tetzcocana en la Conquista también tuvo un fin pragmático. Desde la memoria histórica, Alva luchó por justificar, defender y exigir los justos privilegios y el estatus social que su familia y su persona merecían por los servicios prestados a la Corona y a Dios. En este sentido, su obra más detallada sobre el evento, el Compendio histórico..., adquirió las características de una poderosa relación de méritos y servicios. Su efectividad quedó demostrada en la impresión que las autoridades indígenas de Otumba tuvieron de Ixtlilxóchitl al aprobar su obra,

108 Alva Ixtlilxóchitl, Compendio, f. 23r, en Códice Chimalpahin, v. II, BNAH. 
pues según sus propias palabras "si fuere otro historiador, de ninguna manera hubiéramos hecho esta aprobación”; ${ }^{109}$ y en el reconocimiento que las autoridades españolas le extendieron al otorgarle los cargos a los que tuvo acceso, en donde lo consideraron "persona de satisfacción y confianza" y "propincuo y legítimo sucesor de los reyes que fueron de la dicha ciudad de [Tetzcoco]"110 a pesar de sus endebles vínculos con la nobleza local (Benton); y en la posibilidad de conservar el cacicazgo de San Juan Teotihuacan para sus hijos, una situación que le resultó apremiante ante el olvido amenazante que recorría la región antiguamente gobernada por los aculhuas, y que para él resultaba en un recurso de memoria inevitable para preservarse entre los señores de la tierra.

\section{FuENTES}

\section{Documentales}

Códice Chimalpahin, Biblioteca Nacional de Antropología e Historia. Archivo General de la Nación, México, Indiferente Virreinal.

\section{Obras publicadas}

Adorno, Rolena. Guaman Poma. Literatura de resistencia en el Perú colonial. México: Fondo de Cultura Económica, 1991.

Alva Ixtlilxóchitl, Fernando. History of Chichimeca Nation. Don Fernando de Alva Ixtlilxochitl's Seventeenth-Century Chronicle of Ancient Mexico. Norman: University of Oklahoma Press, 2019.

Alva Ixtlilxóchitl, Fernando. Obras históricas. Incluye el texto completo de las llamadas Relaciones e Historia de la nación chichimeca en una nueva versión establecida con el cotejo de los manuscritos más antiguos que se conocen. México: Universidad Nacional Autónoma de México, Instituto de Investigaciones Históricas, 1975-1977.

Alva Ixtlilxóchitl, Fernando. [Thirteenth Relation: On the Arrival of the Spaniards and the Beginning of the Law of the Gospel]. The Native Conquistador: Alva Ixtlil-

109 “Testimonio que dan el gobernador”, v. I, 519.

110 "Nombramiento de Fernando de Alva”, 14. 
xochitl's Account of the Conquest of New Spain. Pensilvania: Pennsylvania State University Press, 2015.

Battcock, Clementina, Rodrigo Martínez Baracs y Salvador Rueda Smithers, comps. Manuscritos mexicanos, perdidos y recuperados. México: Secretaría de Cultura, Instituto Nacional de Antropología e Historia, 2019.

Bayardi, Citlalli. "Figuras retóricas en el Coloquio de los doce de fray Bernardino de Sahagún y el colectivo indígena del Colegio de Santa Cruz de Tlatelolco, 1564." En Hernández y Máynez, eds., El Colegio de Tlatelolco, 2016, 123-148.

Benton, Bradley. The Lords of Tetzcoco. The Transformation of Indigenous Rule in Postconquest Central Mexico. Nueva York: Cambridge University Press, 2017. Benton, Bradley. "The Outsider: Alva Ixtlilxochitl's Tenuous Ties to the City of Tetzcoco." Colonial Latin American Review, v. 23, n. 1 (2014): 37-52, acceso el 26 de febrero de 2020, http://dx.doi.org/10.1080/10609164.2013.877250

Benton, Bradley. "El provecho de la alianza: efectos a largo plazo de la participación tetzcocana en la conquista." En García Loaeza y Costilla Martínez, Nuevos asedios, 2021, 55-75.

Brian, Amber. Alva Ixtlilxochitl's Native Archive and the Circulation of Knowledge in Colonial Mexico. Nashville, Tennessee: Vanderbilt University Press, 2016.

Brian, Amber. "The Alva Ixtlilxochitl Brothers and the Nahua Intellectual Community." En Texcoco: Prehispanic and Colonial Perspectives, coordinación de Jongsoo Lee y Gale Brokaw, 201-218. Boulder: University Press of Colorado, 2014.

Brian, Amber. "The Original Alva Ixtlilxochitl Manuscripts at Cambridge University." Colonial Latin American Review, v. 23, n. 1 (2014): 84-101, acceso el 24 de abril de 2015, http://dx.doi.org/10.1080/10609164.2013.877253.

Brokaw, Galen, y Jongsoo Lee, coords. Fernando de Alva Ixtlilxochitl and his Legacy. Tucson: The University of Arizona Press, 2016.

Cortés, Hernán. “Tercera carta de relación.” En Cartas y documentos, 115-202. México: Porrúa, 1963.

Costilla Martínez, Héctor Alejandro. Fernando de Alva Ixtlilxóchitl y la reconstrucción de la grandeza texcocana. Escritura híbrida y discurso épico en Historia de la Nación Chichimeca. México: Benemérita Universidad Autónoma de Puebla, Facultad de Filosofía y Letras, 2018.

Daneri, Juan José. "¿Tloque Nahuaque o Dios desconocido? El problema de la traducción en la Historia de la nación chichimeca de Fernando de Alva Ixtlilxóchitl." En Morada de la palabra: homenaje a Luce y Mercedes López-Baralt, ed. de William Mejías López, v. 1, 515-521. San Juan: Universidad de Puerto Rico, 2002. "Diligencias de información y probanza de doña Ana Cortés Ixtlilxóchitl." En Alva Ixtlilxóchitl. Obras históricas, 1975, 294-333. 
Douglas, Eduardo de Jesús. In the Palace of Nezahualcoyotl. Painting Manuscripts, Writing the Pre-Hispanic Past in Early Colonial Period Tetzcoco, Mexico. Austin: University of Texas Press, 2010.

Frost, Elsa Cecilia. "Los colegios jesuitas.” En Historia de la vida cotidiana en México. II: La ciudad barroca, coord. de Antonio Rubial, 307-334. México: Fondo de Cultura Económica; México: El Colegio de México, 2005.

García Loaeza, Pablo. "Deeds to be Praised for All Time: Alva Ixtlilxochitl's Historia de la nación chichimeca and Geoffrey of Monmouth's History of the Kings of Britain." Colonial Latin American Review, v. 23, n. 1 (2014), 53-69, acceso el 21 de noviembre de 2020, en http://dx.doi.org/10.1080/10609164.2013.877251

García Loaeza, Pablo. "Ixtlilxóchitl, flor de la caballería en la conquista de México." En García Loaeza y Costilla Martínez, eds., Nuevos asedios, 2021, 199-217.

García Loaeza, Pablo. “Los manuscritos de don Fernando de Alva Ixtlilxóchitl.” En Battcock, Martínez Baracs y Rueda Smithers, comps., Manuscritos mexicanos, 2019, 171-181.

García Loaeza, Pablo. “Tetzcoco en la conquista.” En De Catemaco a Tezcoco: origen y desarrollo de una ciudad indígena, coordinación de Javier Eduardo Ramírez, 93-117. Texсосо: Diócesis de Texcoco, 2017.

García Loaeza, Pablo y Héctor Costilla Martínez, eds. Nuevos asedios a la conquista de México. Lima: Latinoamericana editores; Lima: Centro de Estudios Literarios Antonio Cornejo Polar, 2021.

Hernández, Esther, y Pilar Máynez, eds. El Colegio de Tlatelolco, síntesis de historias, lenguas y culturas. México: Editorial Grupo Destiempos, 2016.

Iglesia, Ramón. "Estado actual de las ciencias históricas." En Iglesia, El hombre Colón, 1994, 26-31.

Iglesia, Ramón. “La historia y sus limitaciones.” En Iglesia, El hombre Colón, 1994, 32-54.

Iglesia, Ramón. El hombre Colón y otros ensayos. México: Fondo de Cultura Económica, 1994.

Inoue Okubo, Yukitaka. "Crónicas indígenas: una reconsideración sobre la historiografía novohispana temprana." Indios, mestizos y españoles. Interculturalidad e historiografía en la Nueva España. Coord. de Danna Levin y Federico Navarrete, 55-96. México: Universidad Autónoma Metropolitana Azcapotzalco, 2007.

Kauffmann, Leisa A. The Legacy of Rulership in Fernando de Alva Ixtlilxochitl's Historia de la nación chichimeca. Albuquerque: University of New Mexico Press, 2019.

Lee, Jongsoo. "Colonial Writings and Indigenous Politics in New Spain: Alva Ixtlilxochitl's Chronicles and the Cacicazgo of Teotihuacan.” En Brokaw y Lee, coords., Fernando de Alva, 2016, 122-152. 
Lee Jongsoo y Galen Brokaw. "Fernando de Alva Ixtlilxochitl and Colonial Indigenous Historiography from the Conquest to the Present." En Brokaw y Lee, coords., Fernando de Alva, 2016, 3-28.

Lesbre, Patrick. La construcción del pasado indígena de Tetzcoco. De Nezahualcóyotl a Alva Ixtlilxóchitl. México: Secretaría de Cultura, Instituto Nacional de Antropología e Historia; Zamora: El Colegio de Michoacán; México: Centro de Estudios Mexicanos y Centroamericanos, 2016.

Lesbre, Patrick. "Historiographie acolhua du premier siècle de la colonisation. Genèse d'une culture métisse." Tesis de doctorado en Historia, Université de Toulouse-Le-Mirail, Institut Pluridisciplinaire d'Études sur l'Amérique Latine à Toulouse, 1997.

Lienzo de Tlaxcala. México: s/e, 1892.

López de Gómara, Francisco. La historia de las Indias y conquista de México, v. II. Zaragoza: Agustín Millán, 1552.

López de Sigüenza, Gabriel. "Carta proemio.” En Carlos de Sigüenza y Góngora, Oriental planeta evangélico epopeya sacro-panegyrica al apóstol grande de las Indias S. Francisco Xavier, 1-6. México: Doña María de Benavides, 1700.

"Mandamiento del virrey marqués de Gelves a don Fernando de Alva Ixtlilxóchitl. Que haga públicas las averiguaciones respecto a don Antonio de la Mota.” En Peñafiel, comp., Manuscritos de Texcoco, 1979, 17.

Matthew, Laura, y Michel Robert Oudijk, eds. Indian Conquistadors: Indigenous Allies in the Conquest of Mesoamerica. Norman: University of Oklahoma Press, 2007.

Matute, Álvaro, y Evelia Trejo. "Lo sublime, un recurso para creer en la historia." Revista de la Universidad de México, n. 18 (2005): 5-16.

Mazzotti, José Antonio. Coros mestizos del Inca Garcilaso. Resonancias andinas. Lima: Fondo de Cultura Económica, 1996.

"Memoria testamentaria de Antonia Gutiérrez, esposa de don Fernando de Alva Ixtlilxóchitl.” En Alva Ixtlilxóchitl, Obras históricas, 1975, v. II, 390-391.

Mignolo, Walter. Historias locales / diseños globales. Colonialidad, conocimientos subalternos y pensamiento fronterizo. Madrid: Akal, 2002.

Münch, Guido. El cacicazgo de San Juan Teotihuacan durante la Colonia, 1521-1821. México: Secretaría de Educación Pública, Instituto Nacional de Antropología e Historia, 1976.

"Nombramiento de Fernando de Alva Ixtlilxóchitl como juez gobernador de Tetzcoco.” En Peñafiel, comp., Manuscritos de Texcoco, 1979, 14-15.

"Nombramiento de juez gobernador de Tlalmanalco a favor de don Fernando de Alva Ixtlilxóchitl y prórroga por un año.” En Alva Ixtlilxóchitl, Obras históricas, 1975, v. II, 336-337. 
O’Gorman, Edmundo. "Estudio introductorio.” En Alva Ixtlilxóchitl, Obras históricas, 1975, v. I, 1-256.

O’Gorman, Edmundo. La historia natural y moral de las Indias del P. José de Acosta (Estudio que se publicará como prólogo a la nueva edición de dicha obra). México: Fondo de Cultura Económica, 1940.

Parsons, Jeffrey R. "Arqueología regional en la cuenca de México: una estrategia para la investigación futura.” Anales de Antropología, v. 26, n. 1 (1989): 157-257.

Pastrana Flores, Miguel. "Historiografía de tradición indígena." En Historia general ilustrada del Estado de México, 2. Etnohistoria. Dir. de María Teresa Jarquín Ortega y Manuel Miño Grijalva, 55-85. Toluca: Gobierno del Estado de México, Secretaría de Educación del Gobierno del Estado de México, Poder Judicial del Estado de México, LVIII Legislatura del Estado de México, Consejo Editorial de la Administración Pública Estatal, 2011.

Peñafiel, Antonio, comp. Manuscritos de Texcoco. México: Innovación, 1979.

“Poesías de don Fernando de Alva Ixtlilxóchitl.” En Alva Ixtlilxóchitl, Obras históricas, 1975, v. II, 267-273.

Romero Galván, José Rubén. "El Colegio de Tlatelolco, universo de encuentros culturales.” En Hernández y Máynez, eds., El Colegio de Tlatelolco, 2016, 10-25.

Romero Galván, José Rubén. “Fernando de Alva Ixtlilxóchitl.” En Romero Galván, coord., Historiografía mexicana. Volumen I. Historiografía novohispana, 2011, 351-366.

Romero Galván, José Rubén. “Introducción.” En Romero Galván, coord., Historiografía mexicana. Volumen I. Historiografía novohispana, 2011, 9-20.

Romero Galván, José Rubén, coord. Historiografía mexicana. Volumen I. Historiografía novohispana de tradición indígena. México: Universidad Nacional Autónoma de México, Instituto de Investigaciones Históricas, 2011.

Ruwet, Wayne. "Los manuscritos de la Bible Society: su historia, redescubrimiento y contenido.” En Battcock, Martínez Baracs y Rueda Smithers, comps. Manuscritos mexicanos, 2019, 13-25.

Schroeder, Susan. "Father José María Luis Mora, Liberalism, and the British and Foreign Bible Society in Nineteenth-Century Mexico." The Americas, v. 50, n. 3 (enero de 1994): 377-397.

“Testimonio que dan el gobernador, alcaldes, regidores del pueblo de San Salvador Quatlacinco del año de mil seiscientos ocho, el día diez y ocho de noviembre, a don Fernando de Alva Cortés [sic], aprobando su historia que escribió del origen, grandeza y hazañas de los tultecas, chichimecas y naciones sujetas a ellos, hasta la conquista de México y pacificación de las tres provincias, declarando que dicha historia concuerda con las que tienen los pueblos de Otumba, 
con muchas otras particulares.” En Alva Ixtlilxóchitl, Obras históricas, 1975, v. I, 517-521.

Vásquez Galicia, Sergio Ángel. "Aportes a la biografía del historiador tetzcocano Fernando de Alva Ixtlilxóchitl." Revista Fuentes Humanísticas, año 27, n. 53 (julio-diciembre 2016): 145-163, http://zaloamati.azc.uam.mx/handle/11191/5227, consultado: 17 de febrero de 2020.

Vásquez Galicia, Sergio Ángel. "Conceptos, ideas y modelos europeos y de tradición indígena en la construcción de un buen gobernante. Nezahualcóyotl en las crónicas de Fernando de Alva Ixtlilxóchitl." En El gobernante en Mesoamérica. Coord. de María Elena Vega Villalobos y Miguel Pastrana Flores, 159-189. México: Universidad Nacional Autónoma de México, Instituto de Investigaciones Históricas, 2018.

Vásquez Galicia, Sergio Ángel. "La identidad de Fernando de Alva Ixtlilxóchitl a través de su memoria histórica. Análisis historiográfico.” Tesis doctoral, Universidad Nacional Autónoma de México, Facultad de Filosofía y Letras, 2013.

Villella, Peter. "The Last Acolhua: Alva Ixtlilxochitl and Elite Native Historiography in Early New Spain." Colonial Latin American Review, v. 23, n. 1 (2014): 18-36, http://dx.doi.org/10.1080/10609164.2013.877249, consultado: 21 de noviembre de 2020.

Whittaker, Gordon. "The Identities of Fernando de Alva Ixtlilxochitl." En Brokaw y Lee, coords., Fernando de Alva, 2016, 29-76.

\section{SOBRE LOS AUTORES}

Clementina Battcock

Es doctora en Historia por la Facultad de Filosofía y Letras de la UNAM, especializándose en estudios sobre las crónicas novohispanas de tradición indígena. Desde 2013 es profesora-investigadora de la Dirección de Estudios Históricos del Instituto Nacional de Antropología e Historia, centro en el que dirige el proyecto Crónicas Novohispanas y Andinas. Su última publicación fue en coautoría con José Rubén Romero Galván, titulada "Chimalpain Cuautlehuanitzin. La transformación del mundo indígena en la construcción de las memorias novohispanas", ubicada en el dossier L'immagine delle religioni indigene nelle cronache novoispane: nuove vie di indagine [La imagen de las religiones indígenas en crónicas novohispanas. Nuevos caminos a transitar], publicado en la revista Studi e Materiali di Storia delle Religioni, v. 86, n. 2 (La Sapienza-Università di Roma, diciembre 2020): 592-607. 
Sergio Ángel Vásquez Galicia

Es licenciado, maestro y doctor en Historia por la UNAM. Especialista en historiografía de tradición indígena y cultura náhuatl. Desde 2014 es profesor de asignatura del Colegio de Historia de la Facultad de Filosofía y Letras de la Universidad Nacional Autónoma de México, en donde imparte la materia Introducción a la Cultura Náhuatl y el seminario Fuentes y Temas de Cultura Náhuatl. Su última publicación es "Los indios del Nuevo Mundo en el esquema cristiano de la historia universal según fray Diego Durán”, Revista de Historia de América, n. 158 (México, enero-junio 2020): 13-40, https://doi.org/10.35424/rha.158.2020.475. 